\title{
Complications associated with removal of the laryngeal mask airway: a comparison of removal in deeply anaesthetised versus awake patients
}

The purpose of the study was to compare the incidence of complications (coughing, biting, retching, vomiting, excessive salivation and airway obstruction) associated with removal of the laryngeal mask airway. The laryngeal mask airway was used in 100 adults undergoing urological procedures. The patients were randomly assigned to two groups. In 50 patients the laryngeal mask was removed by a nurse when the patient responded to commands in the recovery area. In the other 50 patients it was removed by the anaesthetist with the patient deeply anaesthetized in theatre. The majority of patients were elderly men who had relatively short procedures. The incidence of gastric regurgitation was assessed by measurement of $\mathrm{pH}$ of secretions at the tip of the laryngeal mask airway. Complications accurred more frequently in the awake patients ( $P$ $<0.01$ ). Most were minor and occurred before removal of the laryngeal mask airway during emergence in the recovery room. Airway obstruction occurred in three patients in whom the laryngeal mask was removed in the recovery room. In two of these patients the oxygen saturation decreased below $80 \%$ and the other to $90 \%$. No decrease in arterial oxygenation occurred in the anaesthetised patients in whom the laryngeal mask was removed by the anaesthetist. In 14 patients in the awake group the $\mathrm{pH}$ of secretions at the tip of the laryngeal mask was $\leq 3$

Key words

ANAESTHESIA: general;

EQUIPMENT: laryngeal mask airway.

From the Departments of Anaesthesia, Princess of Wales

Hospital, Coity Road, Bridgend. Mid-Glam. CF31 IRQ, and

University Hospital of Wales, ${ }^{*}$ Heath Park, Cardiff CF4 4XW.

Address correspondence to: Dr. P.S. Gataure, The

Department of Anaesthesia, The Princess of Wales Hospital,

Coity Road, Brigend, Mid-Glam. CF31 IRQ.

Accepted for publication 11th August, 1995. compared with only four patients in the anaesthetised group $(P<0.05)$. It is concluded that it may be safer to remove the laryngeal mask airway whilst the patients are deeply anaesthetised in the operating room than when they are awake in the recovery room.

Cette étude a pour objectif de comparer lincidence des incidents (toux, morsures, haut-le-coeur, vomissements, salivation excessive et obstruction des voies respiratoires) associes à l'ablation du masque laryngé. Un masque laryngé est mis en place chez 100 adultes soumis à une intervention urologique. Les patients sont répartis au hasard entre deux groupes. Dans le premier groupe de 50 patients, le masque laryngé est enlevé par linfirmière de la salle de réveil dès que le patient répond aux ordres verbaux. Dans le deuxième groupe, le masque est retiré par l'anesthésiste en salle d'opération alors que le patient est toujours sous anesthésie profonde. La majorité des patients sont des personnes âgées opérées pour des interventions relativement courtes. Lincidence de la régurgitation gastrique est évaluée par la mesure du $\mathrm{pH}$ des sécrétions recueilles à la pointe du masque laryngé. Les complications sont plus fréquentes chez le patient éveillé $(P<0,01)$. La plupart sont mineures et surviennent à la phase d'émergence, avant l'ablation du masque, en salle de réveil. On note de l'obstruction chez trois patients dont le masque a été enlevé à la salle de réveil. Chez deux de ces patients, la saturation en oxygène baisse sous $80 \%$ et chez le troisième à $90 \%$. Cette complication ne survient chez aucun des patients encore sous anesthésie lorsque le masque laryngé est retiré par un anesthésiste. Chez 14 patients du groupe éveillé, le $\mathrm{pH}$ des sécrétions prélevées à la pointe de masque laryngé est de $\leq 3$ comparativement à quatre patients seulement du groupe encore anesthésié $(P<0,05)$. En conclusion, il est préférable pour la sécurité du patient d'enlever le masque laryngé alors quil est encore anesthésié profondément en salle d'opération qu'en salle de réveil à la phase de récupération. 
The laryngeal mask airway (LMA) has greatly modified airway management since it was first described by Brain in $1983 .{ }^{1}$ The LMA is easy to position and provides a secure airway for both spontaneously breathing patients and those whose lungs are mechanically ventilated, undergoing a wide range of surgical operations. ${ }^{2}$ Complications associated with the use of the LMA have been reported at insertion, during maintenance and during recovery. ${ }^{3-5}$

In one study, on the use of the LMA in children, problems (coughing, biting, laryngospasm, retching and vomiting) associated with removal of the LMA occurred in 26 patients (13\%) when they were awake. ${ }^{4}$ In 19 patients there was a single problem, while in seven multiple problems occurred. In all cases removal of the device relieved the problems. In another paediatric study Laffon et al. concluded that it was safer to remove the LMA in deeply anaesthetised patients. ${ }^{6}$

In Intavent instruction manual recommends removal of the LMA when the patient is awake. ${ }^{7}$ In our hospital some anaesthetists remove the LMA from deeply anaesthetised adults in the operating room. The patient is placed in the lateral position, the LMA removed and an oropharyngeal airway is inserted. The patient is then transferred to the recovery room with oxygen supplied by a facemask. Other anaesthetists leave the LMA in situ and transfer the patient lying supine or in the lateral position to the recovery area. Oxygen supply tubing is connected to the LMA via a T-piece system. It is usual for the recovery room nurses to remove the LMA when the patients respond to command. It is not normal practice to insert an oropharyngeal airway in these patients in the recovery room. The purpose of this randomized prospective study was to compare the incidence of complications such as coughing, biting, retching, vomiting, excessive salivation, airway obstruction and regurgitation in two groups of adult patients. In one group the LMA is removed by the anaesthetist in the operating room whilst the patients are deeply anaesthetised, and in the other group the LMA is removed by a recovery nurse when the patients respond to commands.

\section{Methods}

The study was approved by the Local Scientific Committee. After informed consent was obtained, 100 spontaneously breathing patients undergoing urological surgery (ASA I and II) were studied. Patients $<18 \mathrm{yr}$ and those at risk of regurgitation (known or suspected to have a hiatus hernia) were excluded. Fifty patients (anaesthetised group) were randomly allocated to have the LMA removed by the anaesthetist in the operating room while deeply anaesthetised (nitrous oxide and enflurane were not turned off until after removal of the laryngeal mask). The other 50 patients (awake group) had the LMA removed by a recovery nurse when the patient responded to commands.

All patients received temazepam $10-20 \mathrm{mg}$ po as premedication $60 \mathrm{~min}$ before surgery. Before induction of anaesthesia intravenous access was obtained and monitoring commenced (pulse oximetry, ECG and noninvasive BP). Oxygen was administered for three minutes via a facemask. This was followed by induction of anaethesia with alfentanil $(0.25-1.0 \mathrm{mg})$ and propofol (2-3 $\mathrm{mg} \cdot \mathrm{kg}^{-1}$ ) iv. The LMA (size \#3 in women; \#4 in men) was inserted when the depth of anaesthesia was considered to be adequate, and the cuff was inflated with air (20 ml size 3; $30 \mathrm{ml}$ size 4 LMA). The LMA was then connected to a Bain anaesthetic circuit. Ventilation of the lungs was continued until spontaneous respiration returned. Anaesthesia was maintained with enflurane $1-4 \%$ in nitrous oxide and oxygen. Bite blocks were not used in any patient.

At the end of anaesthesia, all patients were turned into the lateral position before removing the LMA. An oropharyngeal airway was inserted in all Group 1 patients before they were transferred to the recovery room breathing $6 \mathrm{~L} \cdot \mathrm{min}^{-1}$ of oxygen via a face mask. Those in Group 2 were transferred to the recovery room breathing oxygen at $6 \mathrm{~L} \cdot \mathrm{min}^{-1}$ via a T-piece. Arterial haemoglobin oxygen saturation $\left(\mathrm{SpO}_{2}\right)$ was monitored in all patients during surgery, during transfer to recovery and for ten minutes after removal of the LMA. The $\mathrm{SpO}_{2}$ was monitored until all patients were fully awake.

The $\mathrm{pH}$ of the secretions at the tip of the LMA was measured with $\mathrm{pH}$ paper after removal of the device in all the patients. A pH of $\leq 3$ was defined as possible evidence of regurgitation.

Information collected included patient characteritics, number of attempts at insertion and associated problems on LMA insertion, duration of operation, $\mathrm{SpO}_{2}$ at one minute intervals during induction, maintenance and recovery, $\mathrm{pH}$ of secretions at the tip of the LMA, and complications (coughing, biting, retching, vomiting, excessive salivation, airway obstruction and regurgitation) before and after removal of the LMA. The anaesthetist recorded the data on all the patients until the patient was transferred to the recovery room. Thereafter patient assessment and data collection was carried by the recovery nurse.

Statistical analysis included Chi-square test for comparison of complications and unpaired $t$ test for comparison of $\mathrm{pH}$ in the two groups of patients.

\section{Results}

The two groups were similar with respect to age, weight, sex, smoking and duration of surgery (Table I). The LMA 
TABLE I Demographic data and duration of surgery (mean (range))

\begin{tabular}{lll}
\hline & $\begin{array}{l}\text { Anaesthetised } \\
\text { group }\end{array}$ & Awake group \\
\hline Age (yr) & $64(30-89)$ & $69(22-86)$ \\
Weight $(\mathrm{kg})$ & $71(40-95)$ & $75(50-101)$ \\
Sex (M/F) & $33 / 17$ & $39 / 11$ \\
Duration of surgery (min) & $30(10-60)$ & $30(10-75)$ \\
No. of smokers & 12 & 16 \\
\hline
\end{tabular}

TABLE II Complications

\begin{tabular}{llc}
\hline & $\begin{array}{l}\text { Anaesthetised } \\
\text { group } \\
(n=50)\end{array}$ & $\begin{array}{l}\text { Awake group } \\
(n=50)\end{array}$ \\
\hline Coughing & 4 & 8 \\
Biting & 3 & 13 \\
Retching & 3 & 5 \\
Vomiting & 0 & 1 \\
Excess saliva & 3 & 14 \\
Airway obstruction & $\frac{0}{10^{*}}$ & $\frac{3}{27 \dagger}$ \\
Total & & 27 \\
\hline
\end{tabular}

*Seven patients had single and three had two problems. $\dagger$ Eighteen patients had single and nine had multiple problems. $P<0.01$.

was correctly inserted at the first attempt in 83 patients, at the second attempt in $\mathbf{1 5}$ and in two patients at the third attempt. The laryngoscope was used to assist placement in seven patients. Trauma at insertion was noted in only one case; the upper lip was cut during insertion.

Complications occurred with removal of the LMA in 37 patients (Table II). In the anaesthetised group complications occurred in ten patients. Complications occurred in this group not at removal of the LMA but later in the recovery room. In the awake group, complications occurred in 27 patients $(P<0.01)$. Most were minor and occurred before removal of the LMA during emergence in the recovery area. In three patients, however, airway obstruction occurred, and in two of these a substantial decrease in arterial haemoglobin oxygen saturation occurred. In these three patients the LMA was removed by a nurse in the recovery room and an anaesthetist was called urgently to render assistance. In the first patient, airway obstruction occurred before the patient was awake, after a bout of coughing, retching and then biting the airway. The $\mathrm{SpO}_{2}$ decreased to $78 \%$. The LMA was removed and the $\mathrm{SpO}_{2}$ recovered to $98 \%$ two minutes after removal of the device. In the second patient, airway obstruction occurred after coughing and retching. The LMA was removed immediately. The $\mathrm{SpO}_{2}$ decreased to $90 \%$ and recovered spontaneously to $98 \%$ within a minute. In the third patient airway obstruction

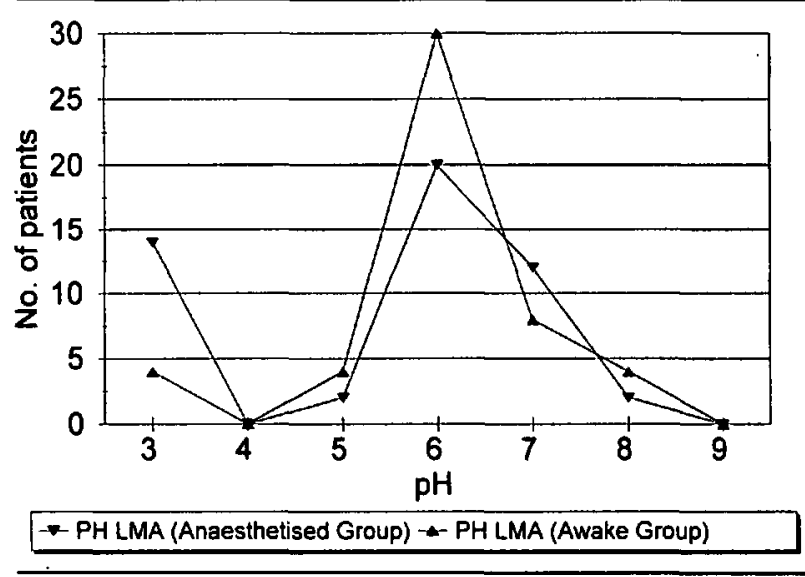

FIGURE $\mathrm{pH}$ of secretions at tip of LMA.

occurred after inspiratory stridor was noticed. The LMA was removed and an oropharyngeal airway was inserted. Inspiratory stridor continued for four minutes. The $\mathrm{SpO}_{2}$ decreased to $80 \%$ two minutes before removal of the LMA and recovered to $98 \%$ four minutes after removal.

The lowest $\mathrm{pH}$ measured for the secretions at the tip of the LMA was 3 . Fourteen patients (28\%) in the awake group and four (8\%) in the anaesthised group had a pH of $3(P<0.05)$ (Figure). None of the patients with complications in the anaesthetised group had a pH of 3 . Ten of 14 patients who had a $\mathrm{pH}$ of 3 in the awake group had complications upon removal of the LMA.

\section{Discussion}

The incidence of complications on removal of the LMA in this investigation was $20 \%$ in the anaesthetised group and $54 \%$ in the awake group $(P<0.01)$. The majority of patients in the study were elderly men presenting for relatively short procedures. Most of the complications occurred in the recovery room where the anaesthetists is not always readily available. Although the incidence of complications appears to be high, most were minor and in only three patients did serious problems occur. In these cases an anaesthetist was urgently called to the recovery room to render assistance. The Intavent instruction manual recommends removal of the device when the patient is awake. However, there appears to be no objective evidence to support this recommendation.

The incidence of regurgitation as reflected by the $\mathrm{pH}$ of secretions at the tip of the LMA is much higher in the awake group (28\%) than in the anaesthetised group (8\%). It would seem that events such as coughing, gagging, retching and biting all increase the likelihood of regurgitation of gastric contents. However, none of the patients in this study had any evidence of aspiration. Bite blocks were not used in any patients taking part in this 
study as most anaesthetists in our hospital do not use them. The routine use of bite blocks may reduce the incidence of biting the LMA. ${ }^{4}$

The incidence of complications in this study is higher than the $13 \%$ quoted by Mason and Bingham. ${ }^{4}$ In their study, all the patients were children and all had the LMA removed when they were awake. Laffon $e t$ al. reported a two-fold increased incidence of complications after removal of the LMA in awake compared to deeply anaesthetised paediatric patients. ${ }^{6}$

Regurgitation and aspiration of gastric contents have been reported. ${ }^{3,8,9}$ One study showed an incidence of regurgitation of $33 \%$ in spontaneously breathing patients, ${ }^{10}$ whilst another could not demonstrate any evidence of regurgitation. " Lower oesophageal sphincter pressure decreased more in patients with an LMA than those with a face mask and airway, ${ }^{12}$ whilst insertion of the LMA did not decrease upper oesophageal sphincter pressure. ${ }^{13}$

The high incidence of complications in the awake group in this study raises the possibility that we are doing something wrong. The Intavent instruction manual ${ }^{7}$ recommends removal of the LMA in the recovery room after the patient has been allowed to wake up without being disturbed. The recovery nurses in our hospital are instructed not to disturb the patient and to remove the LMA when the patient responded to commands, i.e., the patient is awake. Recovery nurses occasionally cut the ribbon with which the LMA is secured. Cutting the ribbon may stimulate some patients, as may other activities such as measuring blood pressure and noise. The Intavent instruction manual states that coughing is not necessarily an indication for removal of the LMA. We believe that if the patient is coughing, excessively, removal of the device may prevent further serious consequences. Mason and Bingham reported that removal of the LMA was the only action required for complications that occurred in paediatric patients in the recovery room. ${ }^{4}$

Our results show that it is not always possible to leave the LMA in situ until the patient is fully awake. This is illustrated by the three patients described above. Most patients tolerate the LMA well if left undisturbed. Occasionally patients take out the LMA themselves under the supervision of the recovery nurse. The LMA is sometimes taken out by the recovery nurse when the patient is gagging or retching. It is difficult to ascertain whether the patient is fully awake at this moment. We were surprised to find a $6 \%$ incidence of airway obstruction in awake patients. We believe that this is higher than the incidence of airway obstruction in current practice. We find it difficult to explain the high incidence of airway obstruction in awake patients. Airway obstruction is now a very uncommon occurrence in our current clinical practice. This may be as a result of the recovery nurses being more familiar with the use of the LMA. Most recovery nurses in our hospital have never had a major complication associated with removal of the LMA.

The results of this investigation suggest that it may be safer to remove the LMA while the patients are deeply anaesthetised in the operating room. However, many anaesthetists prefer to leave the LMA in situ until the patient is awake as this helps to maintain a clear airway until protective reflexes have returned.

\section{References}

1 Brain $A I J$. The laryngeal mask - a new concept in airway management. Br J Anaesth 1983; 55; 801-5.

2 Brodrick PM, Webster NR, Nunn JF. The laryngeal mask airway. A study of 100 spontaneous breathing patients. Anaesthesia 1989; 44: 238-41.

3 Griffin RM, Hatcher IS. Aspiration pneumonia and the laryngeal mask airway. Anaesthesia 1990; 45: 1039-40.

4 Mason DG, Bingham RM. The laryngeal mask airway in children. Anaesthesia 1990; 45: 760-3.

5 Payne J. The use of the fibre optic laryngoscope to confirm the position of the laryngeal mask (Letter). Anaesthesia 1989; 44: 865 .

6 Laffon M, Plaud B, Dubosset AM, Ben Haj'Hmida R, Ecoffey $C$. Removal of laryngeal mask airway: airway complications in children, anaesthetised versus awake. Paediatric Anaesthesia 1994; 4: 35-7.

7 Brain AIJ. The Intavent Laryngeal Mask Instruction Manual, 2nd Ed. 1991: 21-2.

8 Nanji GM, Maltby $J R$. Vomiting and aspiration pneumonitis with the laryngeal mask airway. Can J Anaesth 1992; 39: 69-70.

9 Koehli $N$. Aspiration and the laryngeal mask airway (Letter). Anaesthesia 1991; 46: 419.

10 Barker P, Langton JA, Murphy PJ, Rowbotham DJ. Regurgitation of gastric contents during general anaesthesia using the laryngeal mask airway. $\mathrm{Br} \mathrm{J}$ Anaesth 1992; 69: 314-5.

11 Mikatti N. EL, Luthra AD, Healy TEJ, Mortimer AJ. Gastric regurgitation during general anaesthesia in the supine position with the laryngeal and face mask airways. $\mathrm{Br}$ J Anaesth 1992: 529P-530P.

12 Rabey $P G$, Murphy PJ, Langton JA, Barker P, Rowbotham DJ. Effect of the laryngeal mask airway on lower oesophageal sphincter pressure in patients during general anaesthesia. Br J Anaesth 1992; 69: 346-8.

13 Vanner RG, Pryle BJ, O'Dwyer JP, Reynolds $F$. Upper oesophageal sphincter pressure during inhalational anaesthesia. Anaesthesia 1992; 47: 950-4. 